\title{
Risperidone in the treatment of behavioral disorders associated with autism in children and adolescents
}

\author{
Roberto Canitano \\ Valeria Scandurra \\ Division of Child Neuropsychiatry, \\ University Hospital of Siena, Siena, \\ Italy
}

\begin{abstract}
This is a review of the clinical trials investigating the efficacy and safety of risperidone in the treatment of children with autistic spectrum disorders (ASD). The main clinical characteristics are impairment in social skills, communication difficulties, repetitive movements and behaviors, including stereotypies. Pharmacotherapy is mainly directed at the so-called target symptoms, ie, behavioral disorders and the various kinds of repetitions associated with ASD. According to the available data, risperidone seems to be moderately efficacious and safe for treating behavioral disorders. 4 double blind controlled trial. 3 reanalysis studies, and 12 open studies have documented the role of risperidone in children with ASD. Controlled studies have been thoroughly considered in this review.
\end{abstract}

Keywords: autism, pervasive developmental disorders, risperidone

\section{Introduction}

Autism spectrum disorders (ASD) are characterized by impaired development of social interaction and reciprocity, communication difficulties affecting language and nonverbal skills, and repetitive patterns of movements and behaviors which include restricted interests and activities. Although they are not included in the diagnostic criteria, learning disabilities affect as much as two thirds of individuals with ASD (APA 1994).

They are defined as pervasive developmental disorders (PDDs) in DSM IV classification and include the following diagnostic categories: autistic disorder, Asperger disorder, Rett disorder, childhood disintegrative disorder, and pervasive developmental disorder not otherwise specified (PDD-NOS) including the different forms of atypical autism not matching the diagnostic criteria for the other PDDs.

Autistic disorder (AD), or autism, is the most common PDD/ASD with a recently estimated prevalence of 13 per 10,000. The etiology of AD is still unknown, although genetic factors are probably involved, and in $5 \%$ to $10 \%$ of cases there is an identifiable associated known medical condition. The onset of autistic disorder has been set at before the age of 3 years, and other ASDs may have a later onset (APA 1994). The prevalence of Asperger's disorder is approximately 3 per 10,000 and childhood disintegrative disorder is very rare, estimated at 0.2 per 10,000. Rett disorder prevalence is 1 per 15000 . The prevalence of all PDDs in recent surveys is about 60 per 10,000 (Fombonne 2005).

Behavioral disturbances are fairly common in these disorders and are very often challenging to treat. Tantrums, aggressive behavior, and overactivity/hyperactivity are frequent from the early phases and may last throughout adulthood, causing serious problems in adaptation. The severity and the development of the various symptoms 
and their clinical features vary on an individual basis. When behavioral problems interfere with general wellbeing, daily activities, and with the therapeutic program, pharmacological intervention should be considered (Aman 2004). The so-called target symptoms are therefore tackled by pharmacotherapy with a symptom-based approach. Antipsychotics have been used to control aggression, self-injurious behavior and overactivity/hyperactivity in ASD. Typical antipsychotics have been found to be useful in limiting temper tantrums, hyperactivity, and repetitive movements, and they have also been reported to be effective in improving social interaction. Typical antipsychotics have been extensively used clinically in ASD, but they have not been extensively evaluated, with the exception of Campbell's studies with haloperidol (Campbell et al 1997). Unwanted extrapyramidal effects (UEE) have been a major drawback in the use of these agents and the advent of atypical antipsychotics has provided a safer option in the therapeutic approach to ASD. Furthermore, movement disorders are often difficult to evaluate in this patient population since unusual stereotipies and repetitive movements are part of the core disorder, thus it is often difficult to distinguish between movement disorders that are intrinsic to ASD and those that are possibly related to treatment (Campbell et al 1999).

Atypical antipsychotics, such as risperidone, are being studied for the treatment of behavioral symptoms in ASD due to their increased safety and efficacy compared to conventional neuroleptics (Barnard et al 2002). Most data have been collected on the use of risperidone in children aged 5 and older, but there is still a lack of research in preschool children (Chavez et al 2006; West and Waldrop 2006; Jesner et al 2007). This paper reviews the use of risperidone in children and adolescents with ASD, particularly regarding the treatment of associated behavioral disorders.

\section{Method}

A MEDLINE/Pubmed search was performed, ending in February 2007, on the use of risperidone in children with ASD. The key words used were: autism, pervasive developmental disorders and risperidone. A total of 4 double-blind, placebo controlled trials were found and 2 additional studies were also found which were based on the reanalysis of the data. The results of these studies have been reviewed and summarized below (Table 1). Furthermore, 12 open label, several observational or retrospective trials and case reports have also been published. They are synthetically presented in Table 2.

\section{Risperidone efficacy and safety in children and adolescents with ASD}

- The RUPPAN study (McCracken et al 2002) [ages: 5-17 yrs; risperidone dose: $1.8 \mathrm{mg} /$ day; outcome measurement: ABC-I (and CGI-I); percentage of improvement 69\%].

The first RUPPAN (Research Units on Pediatric Psychopharmacology Autism Network) trial was conducted in a group of children with a diagnosis of autistic disorder as defined in the DSM-IV. Additional inclusion criteria were behavioral disturbances: aggression, hyperactivity, selfinjury and tantrums in varying combinations. The irritability subscale of the aberrant behavior checklist (ABC) was used to rate these symptoms and a score of at least 18 was required for inclusion in the study (Aman et al 1985). The assessment was carried out twice to confirm that the entry criteria had been met. The two groups were made up of 49 and 52 children, with a total of 82 boys and 19 girls.

The Clinical Global Impression - Severity (CGI-S) scale was used to evaluate the children's symptoms at baseline, and the Clinical Global Impression - Improvement scale (CGI-I) was used to evaluate changes during the trial. Eighteen children were found to have moderate severity on the CGI-S, 55 were rated as having marked severity, 24 had severe impairment, and 1 child had extreme impairment. No statistically significant differences were found in any of the baseline scores between the two treatment groups.

The dosage of risperidone was established on the basis of the weight of patients. The starting dose was $0.25 \mathrm{mg} /$ day if the child's weight was less than $20 \mathrm{~kg}$, and $0.5 \mathrm{mg}$ if the child's weight was between 20 and $45 \mathrm{~kg}$, and in this case the dose was increased to $0.5 \mathrm{mg}$ twice daily on day 4 . The titration scheme was the following: for children weighing less than $45 \mathrm{~kg}$, the dose was increased by $0.5 \mathrm{mg}$ according to the clinical response. For children weighing $45 \mathrm{~kg}$ or more, dose increase was accelerated without specifying the actual doses. Maximum dosage was $2.5 \mathrm{mg}$ for children weighing less than $45 \mathrm{~kg}$, and $3.5 \mathrm{mg}$ for children weighing $45 \mathrm{~kg}$ or more.

Primary outcome measures were the Irritability subscale of the $\mathrm{ABC}$, considering a score of 18 as the population average, and the rating on the CGI-I. A decrease in the irritability score was detected in the risperidone group $(\mathrm{p}<0.001)$. Seventy-five percent of children on risperidone were rated as much improved or very much improved on the CGI-I versus $11.5 \%$ of children in the placebo group $(\mathrm{p}<0.001)$. Participants had to have at least a $25 \%$ reduction in the irritability subscale and a rating of much improved or very much 
Table I Clinical trials of risperidone for children with ASD/PDD

\begin{tabular}{|c|c|c|c|c|c|}
\hline & Design & Pts.(N) & Age (y) & $\begin{array}{l}\text { Mean dose } \\
(\mathrm{mg} / \text { day })\end{array}$ & Results \\
\hline RUPPAN (2002) & $8 w k, D B, P C$ & 101 & $5-17$ & 1.8 & $\begin{array}{l}\text { Improvement on } A B C \text { in irritability, } \\
\text { stereotypy, hyperactivity; improved } \\
\text { CGI-I }\end{array}$ \\
\hline Shea (2004) & Reanalysis 8 wk, DB, PC & 79 & $5-12$ & 1.48 & $\begin{array}{l}\text { Improvement in irritability, } \\
\text { stereotypy hyperactivity, insecurity/ } \\
\text { anxiety; oversensitivity in } A B C \text { and } \\
\mathrm{N}-\mathrm{CBRF} \text {, also in language and social } \\
\text { withdrawal }\end{array}$ \\
\hline RUPPAN (2005) & $\begin{array}{l}\text { Reanalysis } 4 \mathrm{mo}, \mathrm{OL} \text {, } \\
\text { followed for } 8 \text { wk, DB, } \\
\text { PC discontinuation } \\
\text { phase }\end{array}$ & 63 & $5-17$ & 2.08 & $\begin{array}{l}\text { Improvement in ABC in irritability; } \\
\text { continued improvement on CGI-I; } \\
\text { during discontinuation phase, } \\
\text { placebo-treated pts. relapsed more } \\
\text { often and sooner }\end{array}$ \\
\hline McDougle (2005) & $\begin{array}{l}\text { Reanalysis of Database } \\
\text { from RUPPAN ( } 8 w k \\
\text { DB, PC) }\end{array}$ & 101 & $5-17$ & 1.8 & $\begin{array}{l}\text { No improvement in social and } \\
\text { communication skills; improve- } \\
\text { ment in sensory motor behaviors, } \\
\text { affective reactions; decreased } \\
\text { stereotypy on CY-BOCS }\end{array}$ \\
\hline Luby (2006) & $6 \mathrm{mo}, \mathrm{DB}, \mathrm{PC}$ & 24 & $2.5-6$ & $0.5-1.5$ & $\begin{array}{l}\text { Improvement in core symptoms } \\
\text { (CARS) }\end{array}$ \\
\hline Pandina (2006) & $\begin{array}{l}\text { Reanalysis of Database } \\
\text { from RUPPAN ( } 8 w k \\
\text { DB, PC) }\end{array}$ & 55 & $5-12$ & 1.48 & $\begin{array}{l}\text { Hyperactivity, aggression and } \\
\text { irritability }\end{array}$ \\
\hline Nagaray (2006) & $6 \mathrm{mo}, \mathrm{DB}, \mathrm{PC}$ & 40 & $2-9$ & $I^{*}$ & CARS, C-GAS \\
\hline
\end{tabular}

Abbreviations: ABC,Aberrant Behavior Checklist;ASD/PDD, autism spectrum disorder/pervasive developmental disorders; CGI-I, Clinical Global Impression-Improvement; CY-BOCS, Children's Yale-Brown Obsessive Compulsive Scale; DB, Double-blind; N-CBRF, Nisonger-Child Behavior Rating Form; OL, open-label; PC, placebo-controlled; R-FRLRS, Ritvo-Freeman Real Life Rating Scale; RUPPAN, Research Units on Pediatrics Psychopharmacology Autism Network; I mg, *Fixed Dose.

Table 2 Open-label studies of risperidone in children with autism

\begin{tabular}{|c|c|c|c|c|}
\hline & Pts. (n) & Age (ys) & $\begin{array}{l}\text { Mean dose } \\
(\mathrm{mg} / \text { day })\end{array}$ & Results \\
\hline $\begin{array}{l}\text { Fisman and Steele } \\
\text { (1996) }\end{array}$ & 14 & $9-17$ & 1.1 & $\begin{array}{l}\text { I3 pts. Improved on CGAS, agitation, anxiety, } \\
\text { disruptive behaviors, social awareness }\end{array}$ \\
\hline McDougle (1997) & 18 & $5-18$ & 1.8 & $\begin{array}{l}\text { I2 pts. improved on CGI-I, repetitive behavior, } \\
\text { aggression, impulsivity }\end{array}$ \\
\hline Findling (1997) & 6 & $5-9$ & 1.1 & $\begin{array}{l}\text { Effective in all } 6 \text { pts. in problematic behaviors; } \\
\text { improvement on CPRS and CGI-I }\end{array}$ \\
\hline Nicolson (1998) & 10 & $4-10$ & 1.3 & 8 of 10 showed improvement on CPRS and CGI-I \\
\hline Zuddas (2000) & 11 & $7-17$ & 2.7 & $\begin{array}{l}\text { Improvement in behavioral symptoms in } 10 \text { pts.; } \\
\text { results maintained for } 12 \text { months }\end{array}$ \\
\hline Masi (200I) & 24 & $3.6-6.6$ & 0.5 & 8 pts. showed improvement on CPRS and CGI-I \\
\hline Diler (2002) & 20 & $3-7$ & 1.5 & I3 pts. had a positive response on CGI-I \\
\hline Malone (2002) & 22 & $3-16$ & 1.8 & $\begin{array}{l}\text { Significant improvements in CPRS and CGI-I for } \\
10 \text { pts. }\end{array}$ \\
\hline Gagliano (2004) & 20 & $3-10$ & 1.3 & 8 showed improvement on CPRS and CGI-I \\
\hline Troost (2005) & 36 & $5-17$ & 1.8 & $\begin{array}{l}24 \text { pts. where considered responders. In the } \\
\text { double-blind discontinuation phase, } 8 \text { out of } 12 \text { on } \\
\text { placebo relapsed vs } 3 \text { out of } 12 \text { on risperidone. }\end{array}$ \\
\hline Raush (2005) & 13 & $6-12$ & 1.0 & 9 pts. had reduction in SAN \\
\hline Canitano (2006) & 11 & $6-10$ & 0.6 & $\begin{array}{l}\text { Reduction in frequency of self-injurious behaviors } \\
\text { in } 9 \text { pts. YAPA-SIB }\end{array}$ \\
\hline
\end{tabular}

Abbreviations: C-GAS, Children's Global Assessment Scale; CGI-I, Clinical Global Impression-Improvement; CPRS, Children's Rating Scale; PDD, pervasive developmental disorders; SANS, Scale for Assessment of Negative Symptoms;YAPA-SIB, Yale-Paris Self-Injurious Behavior Scale. 
improved in the trial in order to be considered as responders. Accordingly, 34 (69\%) of the 49 children were responders in the risperidone group and $6(12 \%)$ of the 52 in placebo group. Hyperactivity and stereotypy subscales of ABC as secondary measures also showed an improvement in the risperidone group.

The most frequently observed side effects were weight gain, increased appetite, fatigue, drowsiness, drooling, dizziness, constipation, tremor, and tachycardia. The average weight gain was $2.7 \pm 2.9 \mathrm{~kg}$. Improvement was observed in the majority of children by week 4 . Three children in the risperidone group withdrew due to a lack of effectiveness compared to 18 withdrawals in the placebo group.

A 4-month open-label extension of the trial was accepted by $23(68 \%)$ of the children labeled as positive responders and all of them maintained the positive trend during that period.

- The McDougle study (McDougle et al 2005) [reanalysis to assess stereotypy/repetitive behaviors, outcome measurement: CY-BOCS; effect size $d=0.55 ; 69 \%$ percent improvement. Responders were subsequently enrolled in the open label and discontinuation phase].

The RUPPAN database was then used by McDougle and colleagues (2005) to further develop the analysis of risperidone efficacy. The aim of this study was to verify risperidone efficacy on the core symptoms of autism (social impairment, communication deficits, stereotypies). The variation of repetitive movements and behaviors, including stereotypies, is particularly important for the purpose of this review and is presented in detail. A modified version of the Children Yale-Brown obsessive compulsive scales (CY-BOCS) was used to assess these aspects because of the difficulties in language and expression of children with autism. This is a 10 item clinician rated scale normally used for obsessive-compulsive disorder, and the CY-BOCS score in this study was 20 points. At week 8 , a significant reduction of repetitive behaviors was observed in the risperidone group (score decrease from $15.51 \pm 2.73$ to $11.65 \pm 4.2$, and in the placebo group from $15.18 \pm 3.88$ to $14.21 \pm 4.821$, $\mathrm{p}=0.005)$.

Patients who had a positive response to the 8 week trial were given the option of entering the 4-month open-label phase of the study. Furthermore, nonresponders to placebo were given the option of participating in an 8-week openlabel treatment with risperidone. If they had a positive response, they were given a further option of entering the 4-month open-label phase.
At the end of the 4 months, responders entered the discontinuation phase. They were randomly assigned to continue risperidone treatment or to be tapered off to placebo. A total of 63 patients entered the 4-month open-label phase. The two primary outcome measurements were the irritability subscale on ABC and CGI-I. A total of 51 (81\%) subjects completed the open-label phase and all the children continued to show a positive response to the treatment. Twelve children withdrew from this phase, 5 because of loss of efficacy. The most common adverse events were increased appetite and sedation. Of the 51 patients who completed the open-label phase, 38 entered the discontinuation phase. Ten out of 16 patients in the placebo group and 2 out of 16 in the risperidone group had a relapse. The median time periods to relapse were 34 and 57 days in the placebo and risperidone groups, respectively.

- The Shea study (Shea et al 2004) [ages: 5-12 yrs, risperidone dose; $0.06 \mathrm{mg}$; outcome measurement: ABC-I score; percentage of improvement: $64 \%$ of children].

Shea and colleagues (2004) conducted an 8-week double blind, placebo-controlled study of risperidone for the treatment of disruptive behavioral symptoms in children and adolescents with ASD (Schopler et al 1980). The participants had to meet DSM-IV criteria for autism or other PDD and had to have a score of at least 30 on the Childhood Autism Rating Scale (CARS) with or without mental retardation (RUPPAN 2005) The final mean dose was $0.05 \mathrm{mg} / \mathrm{kg} /$ day with a maximum mean dose of $0.06 \mathrm{mg} / \mathrm{kg} / \mathrm{day}$. Forty-one of the 79 children were randomized to receive risperidone and 39 received placebo, and at the end of the trial, the participants showed $64 \%$ and $31 \%$ improvement in the ABC irritability subscale, respectively. Notably, a significant decrease in the $\mathrm{ABC}$ subscales exploring the core symptoms of ASD, such as inappropriate speech and lethargy/social withdrawal, was also observed. Furthermore, a significant decrease was observed in hyperacitvity/compliance ABC subscales and in the Nisonger Behavior Rating Form (NCBRF) subscales of conduct, insecure/anxious, hyperactive and oversensitivity (Aman et al 1996). With the use of CGI-I, 21 (51\%) patients on risperidone were rated as much improved or very much improved compared to only $7(18 \%)$ patients in the placebo group ( $\mathrm{p}<0.005)$.

Somnolence was the most common side effect in children on risperidone. The mean weight gain in the risperidone group was $2.7 \mathrm{~kg}$, while in the placebo group it was $1.0 \mathrm{~kg}$. Tachycardia, upper respiratory infections, and rhinitis occurred more frequently in the risperidone group. Unwanted 
extrapyramidal side effects were reported in 11 patients on risperidone and in 5 on placebo, tremor, and hypokinesia were the most common.

- The Pandina reanalysis study (Pandina et al 2007) [outcome measurement: ABC-I, ABC-I plus CGI-I; effect size: 0.7 ; composite score responders: $58.3 \%$ ].

A secondary analysis of the data of Shea's study was conducted by Pandina and colleagues (2007) to further evaluate the efficacy and safety of risperidone treatment (Nicolson et al 1998). The same behavior and clinical assessment measurements used in the RUPP study were carried out and evaluation of the current most disturbing symptoms was also included. Primary efficacy measurement was the irritability subscale of the $\mathrm{ABC}$, and secondary efficacy measurements were the same as those used in Shea's study (ABC subscales scores and N-CBRF subscale scores, The visual analog scale for the most troublesome symptom (VAS-MS) and CGI-I). As a post-hoc analysis, treatment response was determined by identifying composite responders with an improvement of $>25 \%$ in the ABC-irritability subscale plus a CGI-I score of $<2$ (eg, much or very much improved) for a composite score. A total of $80 \mathrm{ASD}$ patients were enrolled in Shea's original study, and of these 55 were children with a diagnosis of autistic disorder according to the DSM-IV. A CARS score of $>30$ was also required for inclusion in the study.

Twenty-five $(92.6 \%)$ of subjects receiving risperidone and $24(85.7 \%)$ of the placebo group completed 8 weeks of treatment. Subjects dropped out of the risperidone group due to insufficient response (1) and extrapyramidal disorders (1). The changes in the VAS for the most troublesome symptom data were also favorable in the risperidone group. CGI-I and composite response $(>25 \%$ ABC irritability subscale and CGI-I much or very much improved) endpoint changes further confirmed that children in the risperidone group had undergone a significant improvement. There was also a consistent reduction in hyperactivity and aggression, the most troublesome symptoms mentioned by parents, in the risperidone group.

This secondary analysis showed that risperidone was superior to the placebo in controlling behavioral disturbances in more than half of the participants. Among the adverse events reported, weight gain was mild, perhaps due to the low doses of risperidone used, at a mean dose of $1.37 \mathrm{mg} /$ day vs $1.8 \mathrm{mg}$ /day in the RUPP trial. The small sample size and the brief duration of the study were the major limitations.

\section{Risperidone safety and efficacy in preschool children with ASD: age $2.5-6$ years}

Studies of the efficacy of risperidone in the treatment of ASD among preschool children have been extremely limited and are mostly case reports or open-label trials. The largest available open-label study was conducted on preschoolers with ASD, aged 3.9-6.6 yrs, by Masi and colleagues (2003). The significant finding was that core social impairment and verbal and nonverbal communication skills improved, which most previous studies had failed to demonstrate. To date, there have been two controlled studies of risperidone in children with ASD.

- Luby's study (Luby et al 2006) [ages 2.5-6 yrs, risperidone dose 0.5-1.5 mg; CARS score; effect size 0.95].

This was the first double blind controlled study on risperidone in the treatment of preschool children with ASD (Jesner et al 2007). The aim of this research was to test the safety and effectiveness of this medication and to discover whether it could improve the core deficits of ASD as well as interfere with behavioral symptoms. Children with PDDNOS not otherwise specified and those undergoing behavioral treatment were included in the study in order to have a wider population of patients with ASD. Twenty four preschool children aged 2.5-6 yrs who met DSM-IV diagnostic criteria for autism or PDD were recruited for participation. The principal outcome measurements were CARS and the Gillian autism rating scale that were administered at baseline, 2, 4, and 6 months. Socialization and adaptive behavior were assessed at baseline and at the 6-month endpoint with the Vineland adaptive behavior scales. Risperidone was administered in low doses and the final mean daily dose was $0.05 \mathrm{mg} / \mathrm{kg}$. The duration of treatment was 6 months. Safety and efficacy of treatment over the 6-month period was satisfactory. Side effects were relatively mild, as were weight gain, hypersalivation, and higher prolactin levels.

An overall amelioration, measured by means of the difference between CARS scores at baseline and at the end of treatment, was observed in this study in children receiving risperidone compared to those receiving placebo. However, it should be noted that many of the subjects of both groups were undergoing intensive behavioral treatment and different interpretations could be offered regarding the effect of this concomitant treatment. No specific improvements in autism domains were observed as a function of the treatment group, and this is in line with the findings of the other double-blind 
trials with risperidone in older children with ASD. This means that the core social and communication impairment of ASD were only mildly, if at all, affected by the treatment. The decrease in stereotypies, repetitive behaviors and hyperactivity obtained with risperidone therapy had a positive effect on the global functioning of children. A lack of objective measures other than symptoms expression and the lack of a more detailed assessment and structured clinical interview for ASD were the major limitations. Furthermore, the small number of subjects did not allow firm conclusions.

- Nagaraj's study (Nagaraj et al 2006) [ages $<6$ yrs, risperidone dosage $1 \mathrm{mg}$ /day as a fixed dose, $63 \%$ improvement on CARS score].

A double-blind placebo controlled study in preschool children with ASD, aged $<6$ yrs, was conducted by Nagaraj and colleagues (2006) to test the efficacy of risperidone in limiting irritability, aggressive behavior and hyperactivity and in improving the core symptoms of social and communication impairment (McDougle et al 2005). Forty children with a diagnosis of autism according to the DSM IV were enrolled for a 6 month trial with risperidone. The CARS, CGAS, and Global Impression of Parents were used and the mean changes from baseline to the end of 6 months period were the primary outcome measurements. A fixed dose of $1 \mathrm{mg}$ /day was used to obtain more homogenous group data. Twelve of the 19 (63\%) children in the risperidone group demonstrated an improvement of at least $20 \%$ in CARS however none of the children on placebo showed any favorable variations. On the CGAS, children in the risperidone group showed a score that was increased by at least $20 \%$, and $94 \%$ were considered as improved to some extent or considerably improved according to the Global Impression of Parents rating. This study reported a positive outcome regarding the so-called target symptoms and an improvement in social and global functioning. It should be noted that only social responsiveness and nonverbal communication were considered to be improved, but no significant variations were noted in language, speech or in stereotypies. Therefore core social and communication domains were still prominent affected areas of functioning. With regard to the unwanted effects, in this study mild and transient dyskinesia was seen in three children.

\section{Discussion}

The pharmacological approach in the use of risperidone for treating behavioral disturbances in children with ASD is on the increase, but the existing data are still limited and much caution is recommended when prescribing it in such a vulnerable population as that of children with ASD.

The four randomized control trials of risperidone have demonstrated the moderate and clinically significant benefits in behavioral disturbances control, including disruptive behaviors, hyperactivity, stereotypies, and self-injury. The decreases in repetitive behaviors and self-injurious behavior (SIB) were particularly noteworthy since they are core symptoms of ASD. On the contrary, social and language impairments were only slightly modified by treatment, although results differed between studies. It is important to mention that patients selected for more severe behaviors at baseline, such as those that are probably enrolled in these studies, may show a greater treatment benefit in target symptoms. Consequently, generalization of these findings is not recommended, and further investigations on broader clinical ASD populations are needed.

The multisite trial by the RUPPAN (2005) showed that repetitive movements and behaviors decreased with treatment, whereas social and language skills remained unchanged (McCracken et al 2002). Parents' reports were in agreement with these findings and supported the empirical data (Arnold et al 2003). However, the studies by Shea and colleagues (2004) and Nagaraj and colleagues (2006) also found the amelioration of some core aspects of communication and social withdrawal, but in the latter the outcome measurements and low numbers were insufficient for drawing strong conclusions. Further research is needed to test this hypothesis and to replicate the above findings in larger populations.

Risperidone doses varied from $0.01 \mathrm{mg}$ /day to 0.05 $\mathrm{mg}$ /day, and all the studies started with low doses and then increased them slowly. The initial dose was 0.25 to 0.5 $\mathrm{mg} /$ day once or twice daily, with increments of $0.25 \mathrm{mg}$ or 0.5 every three to seven days until a therapeutic response was reached. Therefore, a flexible schedule of dosing is advisable to coincide with characteristics of the child and to minimize unwanted side effects. Dosing guidelines have been provided in labeling for risperidone in many countries for children from 6-16 years of age, but they are not yet available for pre-school children. Therefore, careful monitoring and slow titration of medication are the mainstays of treatment, particularly in younger children.

Weight gain was the most frequent adverse event, ranging from 1 to $10 \mathrm{~kg}$, at a of $2.7 \mathrm{~kg}$ in the Shea and colleagues (2004) and McCracken and colleagues (2002) studies and $2.96 \mathrm{~kg}$ in preschoolers in the Luby and colleagues study (2006). Weight increase usually stabilizes over time, but it 
is more pronounced during the first 2-3 months of therapy. Several potential long term health risks arise with weight gain, such as hypertension, heart disease, diabetes, and dyslipidemia. Diet and physical activity should be suggested during the early phases of treatment with risperidone to limit weight gain. Sedation is another common side effect, but in most studies it is usually referred to as transient and it has not caused withdrawal or any other major effect.

An increase in prolactin levels is very common but monitoring is not required since the higher levels are predictive of clinical symptoms. In the pooled data of the clinical trials the rise in mean values was observed during the first two months of therapy (Findling et al 2003; Anderson et al 2007). It is not yet possible to provide recommended levels of prolactin to be maintained during risperidone treatment due to the lack of data, but clinical monitoring of potentially related symptoms is recommended.

The occurrence of UEE was relatively low in these trials and it must be emphasized that they occur at high doses of risperidone. The maximum mean dose used was $2.08 \mathrm{mg}$ / day, in the low range, and this was probably a conservative approach which limited the occurrence of UEE. Once more, careful clinical monitoring is needed during risperidone treatment because the many common repetitive movements, including complex tics and sterotypies, in children with ASD may mask UEE.

There are still no guidelines for the duration of risperidone treatment in children with ASD. The blinded discontinuation phase of the RUPPAN (2005) study after a 6-month period of double blind risperidone treatment and 4 months of open-label, demonstrated that a relapse in behavioral symptoms was observed in a significant percentage of children on placebo (10 out of 16), 2 months after stopping treatment, and yet this occurred in only 2 out of 16 patients on risperidone.

Several open trials on the use of risperidone in children and adolescents with ASD have been conducted (Table 2). They demonstrated similar overall findings of those obtained by the controlled trials as to the effectiveness of risperidone on three major clinical domains of ASD. Limited effectiveness of risperidone treatment was reported on core language and social impairment in most of them. In the Masi and colleagues (2003) study in preschoolers various degrees of improvement were observed in stereotypies and repetitive behaviors, affect modulation, SIB, and hyperactivity. In these open studies dosage and titration were similar to those used in controlled trials, indicating the general attitude of clinicians to proceed with low titration and to maintain low doses. The principal unwanted effects observed were increased appetite, weight gain and prolactin elevation, are reported in controlled trials (Table 1).

Empirical findings suggest that risperidone should be maintained for a long period, eg, one or more years, using clinical parameters due to the lack of evidence-based guidelines. Treatment studies, including discontinuation studies, suggest is still warranted in ASD after 6 months, but routine periodic re-assessment of the need for continued treatment should be performed. Future investigation should address the important issues of long term follow-up and discontinuation of risperidone, since ASDs are long-lasting lifetime disorders. The main unwanted UEEs to be controlled in long term treatment are tardive dyskinesia and akathisia.

Heterogeneity in study design and evaluation procedures among the different studies limited the critical analysis. Guidelines for pharmacological trials should be applied in future studies in order to obtain more comparable results regarding safety and efficacy of treatment.

Finally the effects on the developing brain are unknown and concern is warranted. It is not known whether or how it could interfere with the maturational processes of the brain. The mechanisms of action that are effective in limiting behavioral disorders in ASD are likewise not yet known and should be investigated. Therefore there are several implications of early risperidone treatment on the neurobiology of development, and further research is needed to elucidate these aspects.

\section{Conclusion}

Moderate efficacy and safety of risperidone for treating maladaptive behaviors, including aggression, hyperactivity, self injury and irritability, have been documented in the available studies. Two studies also found some degree of improvement in some of the core features of ASD. Risperidone was promising in preschoolers with ASD also combined with behavioral interventions. Further trials on larger populations and of longer duration are needed for obtaining more information on the tolerability and efficacy of risperidone at a young age. Furthermore, the different biases, such as the tendency to enroll more severe cases in clinical trials, should be thoroughly controlled in future studies as subgroups of children that could be more responsive to treatment have been considered in current research. Efficacy and tolerability of risperidone in the various types of PDDs, including the different degrees of severity of core symptoms, from mild to severe, are still undetermined and should be appropriately addressed. At present much caution is therefore warranted 
in this vulnerable population that raises additional concerns and that needs continuous care, especially when receiving pharmacotherapy.

\section{References}

Anderson GM, Scahill L, McCracken JT, et al. 2007. Effects of short- and long-term risperidone treatment on prolactin levels in children with autism. Biol Psychiatry, 61:545-50.

Aman MG. 2004. Management of hyperactivity and other acting-out problems in patients with autism spectrum disorder. Semin Pediatr Neurol, 11:225-8.

Aman MG, Singh NN, Stewart AW, et al. 1985. The aberrant behavior checklist: A behavior rating scale for the assessment of treatment effects. Am J Ment Defic, 89:485-91.

Aman MG, Tassé MJ, Rojahn J, et al. 1996. The Nisonger CBRF: A child behavior rating form for children with developmental disabilities. Res Dev Disabil, 17:41-57.

[APA] American Psychiatric Association. 1994. Pervasive developmental disorders. Diagnostic and Statistic Manual of Mental Disorders, 4th edition. Washington, DC: American Psychiatric Association.

Arnold LE, Vitiello B, McDougle C, et al. 2003. Parent-defined target symptoms respond to risperidone in RUPP autism study: Customer approach to clinical trials. J Am Acad Child Adolesc Psychiatry, 42:1443-50.

Barnard L, Young AH, Pearson J, et al. 2002. A systematic review of the use of atypical antipsychotics in autism. J Psychopharmacol, 16:93-101.

Campbell M, Armenteros JL, Malone RP, et al. 1997. Neuroleptic-related dyskinesias in autistic children: a prospective longitudinal study. $J \mathrm{Am}$ Acad Child Adolesc Psychiatry, 36:835-43.

Campbell M, Rapoport J, Simpson G. 1999. Antypsychotics in children and adolescents. J Am Acad Child Adolesc Psychiatry, 38:537-45.

Canitano R. 2006. Self injurious behavior in autism. Clinical aspects and treatment with risperdone. $J$ Neural Trans, 113:425-31.

Chavez B, Chavez-Brown M, Rey JA. 2006. Role of risperidone in children with autism spectrum disorder. Ann Pharmacother, 40:909-16.

Diler RS, Firat S, Avci A. 2002. An open label trial of risperidone in young children with autism. Curr Ter Res Clin Exp, 63:91-102.

Findling R, Kusumakar V, Daneman D, et al. 2003. Prolactin levels during long-term risperidone treatment in children and adolescents. $J$ Clin Psychiatry, 64:1362-9.

Fisman S, Steele M. 1996. Risperidone in pervasive developmental disorders: a case series. J Child Adolesc Psychopharmacol, 6:177-90.

Fombonne E. 2005. Epidemiology of autistic disorder and other pervasive developmental disorders. J Clin Psychiatry, 66:S10:3-8.

Gagliano A, Germano E, Pustorino G, et al. 2004. Risperidone treatment of children with autistic disorder: Effectiveness, tolerability, and pharmacokinetic implications. J Child Adolesc Psychopharmacol, 14:39-47.

Jesner O, Aref-Adib M, Coren E. 2007. Risperidone for autism spectrum disorder. Cochrane Database Syst Rev, 24:CD005040.

Luby J, Mrakotsky C, Stalets MM, et al. 2006. Risperidone in preschool children with autistic spectrum disorders: an investigation of safety and efficacy. J Child Adolesc Psychopharmacol, 16:575-87.
Malone RP, Maislin G, Choudhury MS, et al. 2002. Risperidone treatment in children and adolescents with autism: Short- and long-term safety and effectiveness. J Am Acad Child Adolesc Psychiatry, 41:140-7.

Masi G, Cosenza A, Mucci M, et al. 2001. Open trial of risperidone in 24 young children with pervasive developmental disorders. J Am Acad Child Adolesc Psychiatry, 40:1206-14.

Masi G, Cosenza A, Mucci M, et al. 2003. A 3-year naturalistic study of 53 preschool children with pervasive developmental disorders treated with risperidone. J Clin Psychiatry, 64:1039-47.

McCracken JT, McGough J, Shah B, et al.; Research Units on Pediatric Psychopharmacology Autism Network. 2002. Risperidone in children with autism and serious behavioral problems. $N$ Engl J Med, 347:314-21.

McDougle C, Holmes J, Bronson MR, et al.1997. Risperidone treatment in children and adolescent with pervasive developmental disorders: A prospective open-label trial. J Am Acad Child Adolesc Psychiatry, 36:685-93.

McDougle CJ, Scahill L, Aman MG, et al. 2005. Risperidone for the core symptom domains of autism: Results from the study by the autism network of the research units on pediatric psychopharmacology. Am J Psychiatry, 162:1142-8.

Nagaraj R, Singhi P, Malhi P. 2006. Risperidone in children with autism: randomized, placebo-controlled, double-blind study. J Child Neurology, 21:450-5.

Nicolson R, Awad G, Sloman L. 1998. An open trial of risperidone in young autistic children. $J$ Am Acad Child Adolesc Psychiatry, 37:372-6.

Pandina GJ, Bossie CA, Youssef E, et al. 2007. Risperidone improves behavioral symptoms in children with autism in a randomized, double-blind, placebo-controlled trial. J Autism Dev Disord, 37:367-73.

Rausch JL, Sirota EL, Londino DL. 2005. Open-label risperidone for Asperger's disorder: negative symptom spectrum response. $J$ Clin Psychiatry, 66:1592-7.

[RUPPAN] Research Units on Pediatric Psychopharmacology Autism Network. 2005. Risperidone treatment of autistic disorder: longer-term benefits and blinded discontinuation after 6 months. Am J Psychiatry, 162:1361-9.

Schopler E, Reichler RJ, DeVellis RF, et al. 1980. Toward objective classification of childhood autism: Childhood Autism Rating Scale (CARS). J Autism Dev Disord, 10:91-103.

Shea S, Turgay A, Carroll A, et al. 2004. Risperidone in the treatment of disruptive behavioral symptoms in children with autistic and other pervasive developmental disorders. Pediatrics, 114:e634-e641.

Troost PW, Lahuis BE, Steenhuis MP, et al. 2005. Long-term effects of risperidone in children with autism spectrum disorders: a placebo discontinuation study. J Am Acad Child Adolesc Psychiatry. 44:1137-44.

West L, Waldrop J. 2006. Risperidone use in the treatment of behavioral symptoms in children with autism. Pediatr Nurs, 32:545-9.

Zuddas A, Di Martino A, Muglia P, et al. 2000 Long-term risperidone for pervasive developmental disorder: efficacy, tolerability and discontinuation. J Child Adolesc Psychopharmacol, 10:79-90. 